\title{
Barriers to adherence in adolescents and young adults with cystic fibrosis: a questionnaire study in young patients and their parents
}

This article was published in the following Dove Press journal:

Patient Preference and Adherence

10 October 2011

Number of times this article has been viewed

\author{
Vibeke Bregnballe' \\ Peter Oluf Schiøtz' \\ Kirsten A Boisen ${ }^{2}$ \\ Tacjana Pressler ${ }^{3}$ \\ Mikael Thastum ${ }^{4}$ \\ 'Department of Paediatrics, \\ Aarhus University Hospital, Aarhus, \\ Denmark; ${ }^{2}$ Centre of Adolescent \\ Medicine, University Hospital \\ of Copenhagen, Rigshospitalet, \\ Copenhagen, Denmark; ${ }^{3}$ Cystic \\ Fibrosis Centre, University Hospital \\ of Copenhagen, Rigshospitalet, \\ Copenhagen, Denmark; ${ }^{4}$ Department \\ of Psychology, University of Aarhus, \\ Aarhus, Denmark
}

Background: Treatment adherence is crucial in patients with cystic fibrosis, but poor adherence is a problem, especially during adolescence. Identification of barriers to treatment adherence and a better understanding of how context shapes barriers is of great importance in the disease. Adolescent reports of barriers to adherence have been studied, but studies of their parents' experience of such barriers have not yet been carried out. The aim of the present study was to explore barriers to treatment adherence identified by young patients with cystic fibrosis and by their parents.

Methods: A questionnaire survey of a cohort of young Danish patients with cystic fibrosis aged 14-25 years and their parents was undertaken.

Results: Barriers to treatment adherence were reported by $60 \%$ of the patients and by $62 \%$ of their parents. Patients and parents agreed that the three most common barriers encountered were lack of time, forgetfulness, and unwillingness to take medication in public. We found a significant positive correlation between reported number of barriers and perceived treatment burden. We also found a statistically significant relationship between the reported number of barriers and treatment adherence. A significant association was found between the number of barriers and the reactions of adolescents/young adults and those of their mothers and fathers, and between the number of barriers and the way the family communicated about cystic fibrosis.

Conclusion: The present study showed that the majority of adolescents with cystic fibrosis and their parents experienced barriers to treatment adherence. Agreement between adolescents and their parents regarding the level and types of barriers indicates an opportunity for close cooperation between adolescents, their parents, and health care professionals in overcoming adolescent adherence problems.

Keywords: cystic fibrosis, adolescents, parents, barriers, adherence

\section{Introduction}

Cystic fibrosis is a chronic, progressive, and life-limiting disease that requires daily medical treatment, including physiotherapy and oral and inhaled respiratory medication to minimize deterioration of lung function, and dietary supplementation with pancreatic enzymes and vitamin supplements to prevent malabsorption. Medical treatment for cystic fibrosis is demanding, and adherence to medical treatment is crucial, because poor adherence may imply poor health outcomes. ${ }^{1,2}$ However, poor adherence is notably a problem, especially during adolescence. ${ }^{3,4}$ Rates of adherence to treatment for cystic fibrosis are generally low, and vary depending on the type of treatment, ${ }^{3,5,6}$ age and gender of the patient, ${ }^{4,7}$ and method of assessment. ${ }^{8}$

Several studies have explored the etiology of nonadherence, eg, nonadherence to chest physiotherapy as a result of perceived therapeutic ineffectiveness, ${ }^{9}$ prob-
Correspondence: Vibeke Bregnballe Department of Pediatrics, Aarhus University Hospital, Brendstrupgaardsvej 100, DK-8200 Aarhus N, Denmark

Tel +4561699001

Fax +4589496790

Email vibebreg@rm.dk 
lems with fitting chest physiotherapy into lifestyle, and the physical consequences of chest physiotherapy. ${ }^{10}$ The family and atmosphere in the family also seems to be important. An American study suggests that older children and adolescents who come from families experiencing unhappy and conflicted relationships may be at greater risk of poor adherence to treatment. ${ }^{11}$ Furthermore, higher levels of family cohesion and families with a greater balance between cohesion and flexibility seem to show higher rates of both child-reported and parent-reported adherence. ${ }^{12}$

During the past few years, self-reported barriers to treatment adherence have attracted growing interest. Identifying barriers to adherence and factors in the family as potential barriers to adherence may be of great importance for addressing adherence problems.

The purpose of an American study of children with cystic fibrosis and asthma was to systematically identify barriers to treatment adherence by asking children and their parents about adherence. The investigators found that some of the barriers were the same for the two diseases, whereas others were disease-specific. ${ }^{13}$ However, this study only included children. Barrier scales have been developed and validated for adolescents with other diseases. ${ }^{14,15}$ Two recent studies in the area of cystic fibrosis aimed to identify barriers to adherence experienced by adolescents. ${ }^{16,17}$ Interviews with adolescents and young adults with cystic fibrosis revealed treatment burden as the most frequently noted barrier, ${ }^{16}$ while a questionnaire study of adolescents with cystic fibrosis found forgetting and time management to be the most frequent barriers to adherence. ${ }^{17}$ However, these studies of adolescents with cystic fibrosis did not include the points of view of parents.

The aim of the present study was to explore barriers to treatment perceived by adolescent patients with cystic fibrosis and their parents, and the context in which such barriers arise, with a view to developing strategies to improve adherence. We hypothesized that adolescents and their mothers and fathers would agree upon the level and types of barriers to adherence. Additionally, we hypothesized that a high treatment burden as well as conflicts in the family induce greater barriers to treatment adherence.

\section{Materials and methods Participants and procedures}

Danish patients aged 14-25 years with a confirmed diagnosis of cystic fibrosis $(n=146)$ and their parents $(n=269)$ formed the target group, and were identified from the Danish Cystic Fibrosis Registry. They were introduced to the study by a mailed letter, and data were collected through web-based questionnaires from February 2010 to June 2010. Adolescent and young adult patients are referred to as adolescents in this paper.

\section{Questionnaires}

This investigation was part of a larger exploratory study in which focus groups and individual interviews were conducted to identify areas of concern. Two focus group interviews with adolescents were conducted, comprising one for adolescents aged $14-18$ years $(n=7)$ and another for those aged 19-25 years $(n=6)$, and three individual interviews were conducted with severely ill patients. We sought an equal distribution with regard to gender, age, and disease severity as measured by lung function (forced expiratory volume in one second as percent of predicted $\left[\mathrm{FEV}_{1} \%\right]$ ). One focus group interview $(\mathrm{n}=5)$ and two individual interviews were conducted with the parents. Here we sought an equal distribution with regard to gender, child's gender, age, and disease severity. The key question was, "What can the cystic fibrosis centre do to support the adolescent with cystic fibrosis in the successful transition into adult life? - in the areas of (1) managing the disease in everyday life, (2) balancing between adherence and autonomy, (3) risky behavior and (4) in relation to the parents?" (the last question being for patients only). Analysis of these interviews identified several themes, ie, adherence and issues that may influence adherence, cooperation with parents, cooperation with the cystic fibrosis center, and risky behavior. On the basis of these themes, several questionnaires covering these themes were developed. In this study, we report the results concerning adherence issues only.

Barriers to adherence emerged as a prominent theme during the interviews, so a "barriers to adherence" questionnaire was designed. Adolescent adherence was explored using a separate questionnaire. To explore family matters relevant to adolescent barriers to adherence, four additional questionnaires addressing reactions of the mother, reactions of the father, reactions of the adolescent, and communication about cystic fibrosis within the family were developed, also on the basis of the interviews. The questionnaire about barriers to adherence contained five questions exploring why the adolescent did not take the medication as recommended (Table 1). A Likert scale had four response options, ie, "absolutely right" to "absolutely wrong" and the option "do not know". The "adherence" questionnaire had seven questions on adherence to the recommended daily as well as intermittent medical treatment (Table 1). Here it should be noted that the recommended kind of chest physiotherapy for Danish patients with cystic fibrosis is a positive expiratory pressure mask. A Likert scale with six 
Table I The six questionnaires with internal consistencies (Cronbach's alpha) and test-retest Spearman's correlation

\begin{tabular}{|c|c|c|c|c|c|}
\hline Item & Items (n) & $\begin{array}{l}\text { Adolescent } \\
\text { Cronbach's } \alpha\end{array}$ & $\begin{array}{l}\text { Parent } \\
\text { Cronbach's } \alpha\end{array}$ & $\begin{array}{l}\text { Adolescent test-retest } \\
\text { Spearman's } \\
\text { correlation }\end{array}$ & $\begin{array}{l}\text { Parent test-retest } \\
\text { Spearman's } \\
\text { correlation } \\
\end{array}$ \\
\hline Barriers to adherence & 5 & 0.76 & 0.82 & 0.84 & 0.81 \\
\hline \multicolumn{6}{|l|}{ Difficulty finding time to take CF treatment } \\
\hline \multicolumn{6}{|l|}{ Forgetting to take $\mathrm{CF}$ treatment } \\
\hline \multicolumn{6}{|l|}{ Choose to be with friends instead } \\
\hline \multicolumn{6}{|l|}{ of taking CF treatment } \\
\hline \multicolumn{6}{|l|}{ Too tired to take CF treatment } \\
\hline \multicolumn{6}{|l|}{ Will not take CF treatment in public } \\
\hline Adherence during past month & 7 & 0.73 & 0.88 & 0.95 & 0.86 \\
\hline \multicolumn{6}{|l|}{ Antibiotic tablets } \\
\hline \multicolumn{6}{|l|}{ Pulmozyme $^{\circledR}$} \\
\hline \multicolumn{6}{|l|}{ Positive expiratory pressure mask } \\
\hline \multicolumn{6}{|l|}{ Enzymes } \\
\hline \multicolumn{6}{|l|}{ Vitamins } \\
\hline \multicolumn{6}{|l|}{ Asthma medication } \\
\hline \multicolumn{6}{|l|}{ Inhaled antibiotics } \\
\hline Reactions from mother & 8 & 0.82 & & 0.75 & \\
\hline Reactions from father & 8 & 0.91 & & 0.64 & \\
\hline \multicolumn{6}{|l|}{ Says you are good at remembering treatment } \\
\hline \multicolumn{6}{|l|}{ Scolds you for forgetting treatment } \\
\hline \multicolumn{6}{|l|}{ Asks you to take your treatment although } \\
\hline \multicolumn{6}{|l|}{ you are doing something else } \\
\hline \multicolumn{6}{|l|}{ Quarrels with you about treatment } \\
\hline \multicolumn{6}{|l|}{ Praises your effort to take your treatment } \\
\hline \multicolumn{6}{|l|}{ Helps you only when you ask for help } \\
\hline \multicolumn{6}{|l|}{ Checks that you have taken your treatment } \\
\hline \multicolumn{6}{|l|}{ Trusts that you have taken your treatment } \\
\hline Reactions from adolescent & 5 & 0.91 & & 0.79 & \\
\hline \multicolumn{6}{|l|}{$\begin{array}{l}\text { Get annoyed when parents ask me to take } \\
\text { treatment }\end{array}$} \\
\hline \multicolumn{6}{|l|}{ Tell my parents that I appreciate their help } \\
\hline Get sullen when my parents ask me to ta & & & & & \\
\hline treatment & & & & & \\
\hline Ask parents to mind their own business & & & & & \\
\hline Quarrel with parents about treatment & & & & & \\
\hline Communication about CF in family & 6 & 0.90 & & 0.83 & \\
\hline We communicate openly about CF & & & & & \\
\hline We are good at supporting each other & & & & & \\
\hline when CF takes up all the time & & & & & \\
\hline We can express our feelings towards & & & & & \\
\hline each other regarding CF & & & & & \\
\hline We can talk about everything concerning & & & & & \\
\hline We can talk about our anxiety concernin & & & & & \\
\hline We can communicate about CF although & & & & & \\
\hline we are depressed & & & & & \\
\hline
\end{tabular}

Abbreviation: $\mathrm{CF}$, cystic fibrosis.

response options ranging from "taken the treatment every day" to "missed the treatment every day" and the option "does not get this treatment" was available. We defined three levels of adherence, ie, high adherence ("missed the treatment no more than once during the past month"), medium adherence ("missed the treatment no more than once a week"), and low adherence ("missed the treatment more than once a week").
The questionnaires exploring the reactions of mothers, fathers, and adolescents contained eight questions (Table 1) and a fouroption Likert scale featuring response options from "daily" to "never" and a "not relevant" option. The questionnaire about family communication and support contained six questions (Table 1). We used a four-option Likert scale with response categories from "strongly agree" to "strongly disagree". 
We considered the answers "do not know", "does not get this treatment", and "not relevant" as missing items and substituted them with the mean of the other items.

We consulted multidisciplinary specialist staff and relevant literature to evaluate the relevance of the questions. The questionnaires were pilot-tested in two Danish cystic fibrosis centers (adolescents $n=9$, parents $n=6$ ) to evaluate if the questions were intelligible and relevant.

The internal reliability of each questionnaire was calculated using Cronbach's alpha to assess the association between the items and the questionnaires (Table 1). Items with a Cronbach's alpha below the recommended 0.7 minimum level ${ }^{18}$ were deleted. Other items were deleted for theoretical reasons, eg, items that proved to be obscure when looking at the answers.

Test-retest reliability was tested 10-23 days later in a group of patients $(n=24)$ and a group of parents $(n=61)$ using Spearman's correlation (Table 1). The purpose was to assess the stability of the scores over time, and a correlation higher than 0.80 suggested adequate stability. ${ }^{19} \mathrm{~A}$ paired $t$-test was conducted to measure the difference between the test and the retest to ensure that a correlation was not due to a systematic error.

\section{Other measures}

Forced expiratory volume in one second as a percent of predicted $\left(\mathrm{FEV}_{1} \%\right)$ and body mass index were included as measures of health status. These data were extracted from the National Cystic Fibrosis Registry, and an average of the measures from 2009 was used. The Danish version of the Revised Cystic Fibrosis Quality of Life Questionnaire in adolescents and adults (CFQ-R) was included as a measure of quality of life. ${ }^{20}$

\section{Ethical considerations}

The study was registered with the Danish Data Agency Board. According to Danish law, no particular ethical permission is needed to conduct a study that does not include biomedical aspects, and written consent from the participants is not needed in web-based questionnaire studies. Psychologists, doctors, and nurses at the cystic fibrosis centers were available for psychological support and treatment of patients, if needed. However, no such need was observed.

\section{Statistical analysis}

Descriptive statistics were performed to describe participant demographics, the types and numbers of barriers to adherence, and adherence subgroups. Chi-square tests and
Mann-Whitney U tests were used to determine if differences between participants and nonparticipants and between participants and retest-participants were statistically significant. Adolescent reports of "barriers to adherence" were paired and compared with their mothers' and their fathers' reports of adolescent "barriers to adherence" using the Wilcoxon signed-rank test. The adolescents were divided into two groups, ie, those with one or more barriers to adherence (answered absolutely right or right) and those with no barriers to adherence (answered "absolutely wrong", "wrong", or "do not know") in order to compare the two groups.

Spearman's rank order correlation was conducted to examine the association between barriers to adherence and adherence, reactions from mother, father, and the adolescent, communication about cystic fibrosis, age, body mass index, $\mathrm{FEV}_{1} \%$, and quality of life subscales. No Type I error corrections were made because correlations between most of the variables were expected. The Mann-Whitney U test was performed to compare reactions and communication in the family for the barrier group with those for the no-barrier group.

\section{Results}

\section{Participants}

The questionnaires were completed by $60 \%(n=88)$ of the adolescents and $62 \%(\mathrm{n}=161)$ of the parents. A total of $68 \%(n=93)$ of the mothers and $54 \%(n=68)$ of the fathers completed the questionnaires, with a total of 72 child-mother dyads, 57 child-father dyads, and 60 mother-father dyads. Participant characteristics are shown in Table 2.

The participating adolescents had a statistically significant higher $\mathrm{FEV}_{1} \%$ than the nonparticipating adolescents, and females were significantly more numerous among the participating adolescents, as well as parents than among nonparticipating adolescents and parents (Table 2). The retest participants did not differ significantly from the participants regarding gender, age, body mass index, and $\mathrm{FEV}_{1} \%$ (Table 2).

\section{Reliability and validity}

Cronbach's alpha coefficients ranged from 0.73 to 0.91 (Table 1). Test-retest reliability ranged from 0.64 to 0.95 (Table 1). A paired $t$-test showed no significant difference between the scores in the test and the retest. Content validity, including item coverage, relevance, and face validity of the questionnaires, was validated by experts in cystic fibrosis and adolescence several times during the process of developing 
Table 2 Characteristics of participants, nonparticipants, and re-test participants

\begin{tabular}{|c|c|c|c|c|}
\hline & Participants & Nonparticipants & Significance (two-tailed) & Retest participants \\
\hline Adolescents (n) & 88 & 58 & & 24 \\
\hline Male/female (\%) ${ }^{\mathrm{a}}$ & $40 / 60$ & $64 / 36$ & $0.008^{c}$ & $29 / 71$ \\
\hline Age $(\text { mean } \pm S D)^{b}$ & $19.3 \pm 3.2$ & $18.7 \pm 3.5$ & 0.217 & $19.9 \pm 3.6$ \\
\hline $\mathrm{FEV}, \%(\text { mean } \pm \mathrm{SD})^{\mathrm{b}}$ & $82.6 \pm 22.7$ & $74.8 \pm 22.5$ & $0.046^{c}$ & $77.9 \pm 20.8$ \\
\hline $\mathrm{BMI}(\text { mean } \pm \mathrm{SD})^{\mathrm{b}}$ & $20.6 \pm 3.6$ & $19.9 \pm 2.4$ & 0.381 & $20.5 \pm 4.4$ \\
\hline Parents (n) & 161 & 108 & & 61 \\
\hline Male/female (\%) ${ }^{\mathrm{a}}$ & $42 / 58$ & $57 / 43$ & $0.023^{c}$ & $38 / 62$ \\
\hline Child's FEV ${ }_{1} \%\left(\right.$ mean \pm SD) ${ }^{b}$ & $81.5 \pm 22.9$ & $76.3 \pm 23.3$ & 0.082 & $82.1 \pm 21.9$ \\
\hline
\end{tabular}

Notes: aPearson Chi-square; bindependent-samples Mann-Whitney $U$ test; 'significant at 0.05 level (two-tailed).

Abbreviations: BMI, body mass index; $\mathrm{FEV} \%$, forced expiratory volume in one second as percent of predicted; SD, standard deviation.

the questionnaires. The final versions were considered to be good according to the expert panels, patients, and results of pilot testing.

\section{Barriers to adherence}

Most of the adolescents $(61 \%, n=54)$ reported having one or more adherence barriers. Their experience was acknowledged by most of the mothers $(59 \%, \mathrm{n}=54)$ and fathers $(60 \%$, $n=40)$. The types and frequencies of barriers to adherence are shown in Table 3. The adolescents and their mothers and fathers agreed that the three most common barriers were lack of time, forgetfulness, and unwillingness to take treatment in public (Table 3 ). Wilcoxon signed-rank tests for the childmother $(P=0.75)$, child-father $(P=0.72)$, and mother-father

Table 3 Frequency data for adolescent and parental reports of type and number of barriers to adherence

\begin{tabular}{|c|c|c|c|}
\hline & $\begin{array}{l}\text { Adolescent } \\
\text { reports \% } \\
\text { (n) }\end{array}$ & $\begin{array}{l}\text { Mothers' } \\
\text { reports \% } \\
\text { (n) }\end{array}$ & $\begin{array}{l}\text { Fathers' } \\
\text { reports \% } \\
\text { (n) }\end{array}$ \\
\hline \multicolumn{4}{|l|}{ Types of barriers } \\
\hline $\begin{array}{l}\text { Difficult to find time } \\
\text { to take CF treatment }\end{array}$ & $40(35)$ & $29(27)$ & $3 I(2 I)$ \\
\hline $\begin{array}{l}\text { Forget to take } \mathrm{CF} \\
\text { treatment }\end{array}$ & $40(35)$ & $36(33)$ & $21(14)$ \\
\hline $\begin{array}{l}\text { Choose to be with } \\
\text { friends instead of } \\
\text { taking CF treatment }\end{array}$ & $25(22)$ & $24(22)$ & $16(11)$ \\
\hline $\begin{array}{l}\text { Too tired to take } \\
\text { CF treatment }\end{array}$ & $25(22)$ & $27(25)$ & $19(13)$ \\
\hline $\begin{array}{l}\text { Will not take CF } \\
\text { treatment in public }\end{array}$ & $33(29)$ & $28(26)$ & $37(25)$ \\
\hline Number of barriers & & & \\
\hline 0 barrier & $39(34)$ & $41(38)$ & $40(27)$ \\
\hline I barrier & $17(15)$ & $20(18)$ & $27(18)$ \\
\hline 2 barriers & $14(12)$ & $15(14)$ & $15(10)$ \\
\hline 3 barriers & $11(10)$ & $7(6)$ & $6(4)$ \\
\hline 4 barriers & $12(11)$ & $12(11)$ & $9(6)$ \\
\hline 5 barriers & $7(6)$ & $5(5)$ & $3(2)$ \\
\hline
\end{tabular}

Abbreviation: $\mathrm{CF}$, cystic fibrosis.
$(P=0.73)$ dyads showed no statistically significant differences in their reports of number of adherence barriers.

Adolescent reports of barriers to adherence correlated significantly at the 0.001 level with adherence and treatment burden (Table 4). Significant correlations were also found for most of the other parameters (Table 4). No significant correlation with age was found.

Adolescent adherence varied with the kind of treatment, but in this study we only reported overall adherence. Overall,

Table 4 Correlations between barriers to adherence and adherence, reactions from mother, reactions from father, reactions from adolescent, communication about CF in family, age, BMI, FEV , and CFQ measures

\begin{tabular}{lll}
\hline & $\begin{array}{l}\text { Spearman's } \\
\text { correlation }\end{array}$ & $\begin{array}{l}\text { Significance value } \\
\text { (two-tailed) }\end{array}$ \\
\hline Adherence & 0.54 & $0.00 \mathrm{I}^{\mathrm{a}}$ \\
Reactions from mother & 0.26 & $0.016^{\mathrm{a}}$ \\
Reactions from father & 0.28 & $0.02 \mathrm{I}^{\mathrm{a}}$ \\
Reactions from adolescent & $0.3 \mathrm{I}$ & $0.008^{\mathrm{a}}$ \\
Communication about & 0.26 & $0.016^{\mathrm{a}}$ \\
CF in family & & \\
Age & -0.03 & 0.784 \\
BMI & 0.22 & $0.040^{\mathrm{a}}$ \\
FEV \% average of 2009 measures & 0.15 & 0.164 \\
CF-related quality of life (CFQ) & & \\
Physical functioning & -0.07 & 0.551 \\
Role limitations & -0.23 & $0.030^{\mathrm{a}}$ \\
Vitality & -0.17 & 0.127 \\
Emotional functioning & -0.25 & $0.020^{\mathrm{a}}$ \\
Social functioning & -0.15 & 0.169 \\
Body image & -0.05 & 0.638 \\
Eating disturbances & -0.05 & 0.670 \\
Treatment burden & -0.38 & $0.00 \mathrm{I}^{\mathrm{a}}$ \\
Health perceptions & -0.12 & 0.260 \\
Weight problems & 0.04 & 0.694 \\
Respiratory symptoms & -0.31 & $0.004^{\mathrm{a}}$ \\
Digestive symptoms & -0.28 & $0.009^{\mathrm{a}}$ \\
\hline Notis & &
\end{tabular}

Note: aSignificant at 0.05 level (two-tailed).

Abbreviations: $\mathrm{BMI}$, body mass index; $\mathrm{FEV} \%$, forced expiratory volume in one second as percent of predicted; CF, cystic fibrosis; CFQ, Cystic Fibrosis Quality of Life Questionnaire. 
the adolescents reported lower adherence than their parents did, and those with barriers to adherence reported lower adherence than those with no barriers (Table 5).

Looking at single items in the questionnaires about reactions from mother, father, and adolescent, quarrels and negative reactions were significantly more often reported by the adolescents encountering adherence barriers than by adolescents reporting no barriers (Table 6). Likewise, support and positive communication about cystic fibrosis in the family were significantly more infrequently reported by adolescents with adherence barriers than by those reporting no barriers (Table 6).

\section{Discussion}

Barriers to treatment adherence were reported by $60 \%$ of adolescents and by $62 \%$ of their parents. In other studies, adolescents reported lower rates, ${ }^{17}$ similar rates, ${ }^{16}$ or even higher rates. ${ }^{13}$ The discrepancy between the extent to which barriers are reported in these studies may be attributable to methodological differences. A study comparing reports by children with those of their parents showed higher rates reported by parents than by children. However, the unanimity between the adolescents' and parents' evaluation in the present study is seen as a strength.

The adolescents and their mothers and fathers also agreed that the three most common barriers were lack of time, forgetfulness, and unwillingness to take medication in public. This finding resonates with adolescent reports in other studies, ${ }^{15,17}$ but until now, no reports of parental experience of level and type of barriers have been available. Time management and forgetfulness were also among the most frequent adherence barriers in children with cystic fibrosis and their parents, although oppositional behaviors, taste, and swallowing also seemed to be frequent barriers in those aged 6-13 years. ${ }^{13}$ In adolescents, other studies have reported that fatigue and a preference for being with friends instead of taking medication are also common adherence barriers. ${ }^{16}$ The convergence of the types of barriers was convincing. Thus, the present study adds new information to the existing knowledge by showing parental awareness of adolescent barriers to treatment adherence. This may give health professionals good opportunities for collaborating with adolescents and their parents to improve adherence.

Treatment burden was found to have a significant positive correlation with the number of barriers, which is consistent with a recent study in adolescents. ${ }^{16} \mathrm{~A}$ high level of polypharmacy is thus problematic from the patient perspective. This demands that physicians carefully weigh up the pros and cons in cooperation with the patient before prescribing any additional treatment. The patient is the most obvious person to estimate if an additional treatment can fit in with his or her life. As suggested in another study, health care professionals need to understand not only what is the optimal objective medical condition, but they also need to develop an insight into the subjective experience of living with cystic fibrosis. ${ }^{21}$

The adolescents reported lower adherence than did their parents, whereas other research has shown that adolescents and parents report equal adherence levels. ${ }^{12}$ This discrepancy may be rooted in the subjective and potentially inaccurate nature of self-reported adherence. Furthermore, adolescents may be more accurate reporters than their parents, who may not be fully aware of the adolescent's adherence level. Adolescents encountering barriers reported lower adherence that those who did not, and a statistically significant relationship was found between adherence and the number of barriers. These findings confirm those of other studies. ${ }^{13}$ Identifying adherence barriers and finding solutions to overcome these barriers is important for disease management. The solutions may involve discussion with the adolescent patient about adherence issues and the consequences of nonadherence to establish a workable compromise, as recently suggested. ${ }^{22}$ Discussions may also be initiated on how to prioritize treatment to avoid a situation whereby the adolescent either accepts all treatment or rejects all treatment because of being overwhelmed by lack of time or energy.

A higher number of barriers seemed to correlate with lower body mass index and more digestive and respiratory symptoms. Predictably, the more barriers to adherence, the lower the adherence, and the lower the adherence, the

Table 5 Frequency data for adolescent and parental reports of adolescent adherence

\begin{tabular}{|c|c|c|c|c|}
\hline Report from & $\mathbf{n}$ & High adherence & Medium adherence & Low adherence \\
\hline Adolescents (all) & 88 & $42 \%$ & $43 \%$ & $15 \%$ \\
\hline Parents & 137 & $59 \%$ & $32 \%$ & $9 \%$ \\
\hline Adolescents with one or more barriers to adherence & 54 & $26 \%$ & $56 \%$ & $18 \%$ \\
\hline Adolescents with no barriers to adherence & 34 & $68 \%$ & $23 \%$ & $9 \%$ \\
\hline
\end{tabular}


Table 6 Comparison of mean item scores from the questionnaires exploring reactions from mother, father, and adolescent, and family communication about $\mathrm{CF}$ in the barrier group and the no-barrier group

\begin{tabular}{|c|c|c|c|c|}
\hline & $\mathbf{n}$ & $\begin{array}{l}\text { Adolescents with } \\
\text { barriers mean (SD) }\end{array}$ & $\begin{array}{l}\text { Adolescents with no } \\
\text { barriers mean (SD) }\end{array}$ & $\begin{array}{l}\text { Mann-Whitney U } \\
\text { test significance }\end{array}$ \\
\hline \multicolumn{5}{|l|}{ Reactions from mother ${ }^{\mathrm{a}}$} \\
\hline Says you are good at remembering treatment & 70 & $3.33(0.80)$ & $2.80(0.91)$ & $0.014^{c}$ \\
\hline Scolds you for forgetting treatment & 75 & $1.82(0.91)$ & $\mathrm{I} .46(0.78)$ & 0.069 \\
\hline Asks you to take your treatment although & 72 & $2.17(1.17)$ & $2.20(1.15)$ & 0.906 \\
\hline \multicolumn{5}{|l|}{ you are doing something else } \\
\hline Quarrels with you about treatment & 76 & $1.60(0.73)$ & I.I5 (0.37) & $0.006^{c}$ \\
\hline Praises your effort to take treatment & 69 & $3.22(0.81)$ & $3.00(0.95)$ & 0.392 \\
\hline Helps you only when you ask for help & 63 & $2.77(1.03)$ & $2.22(1.08)$ & $0.042^{c}$ \\
\hline Checks that you have taken your treatment & 76 & $2.31(1.29)$ & $2.32(1.28)$ & 0.950 \\
\hline Trusts that you have taken your treatment & 77 & $1.65(0.55)$ & I.I8 (0.99) & $0.015^{c}$ \\
\hline \multicolumn{5}{|l|}{ Reactions from father ${ }^{a}$} \\
\hline Says you are good at remembering treatment & 59 & $3.50(0.70)$ & $2.83(0.94)$ & $0.004^{c}$ \\
\hline Scolds you for forgetting treatment & 58 & $1.46(0.60)$ & $1.32(0.48)$ & 0.423 \\
\hline Asks you to take your treatment although & 59 & $1.57(0.90)$ & $1.95(1.21)$ & 0.263 \\
\hline \multicolumn{5}{|l|}{ you are doing something else } \\
\hline Quarrels with you about treatment & 62 & $1.35(0.48)$ & $1.09(0.29)$ & $0.027^{c}$ \\
\hline Praises your effort to take treatment & 59 & $3.49(0.65)$ & $2.82(0.91)$ & $0.004^{c}$ \\
\hline Helps you only when you ask for help & 56 & $3.09(0.88)$ & $2.30(1.02)$ & $0.004^{c}$ \\
\hline Checks that you have taken your treatment & 61 & $1.84(1.00)$ & $1.96(1.15)$ & 0.860 \\
\hline Trusts that you have taken your treatment & 65 & $1.78(1.12)$ & $1.28(0.79)$ & $0.034^{c}$ \\
\hline \multicolumn{5}{|l|}{ Reactions from adolescent ${ }^{a}$} \\
\hline Get annoyed when parents ask me to take treatment & 62 & $2.5 \mathrm{I}(\mathrm{I} .12)$ & $2.04(0.93)$ & 0.111 \\
\hline Tell parents that I appreciate their help & 64 & $3.43(0.7 \mathrm{I})$ & $3.29(0.75)$ & 0.467 \\
\hline Get sullen when parents ask me to take treatment & 65 & $2.31(1.07)$ & I.6I (0.66) & $0.010^{c}$ \\
\hline Ask parents to mind their own business & 66 & $1.74(0.88)$ & $1.09(0.29)$ & $0.00 I^{c}$ \\
\hline Quarrel with parents about treatment & 66 & $\mathrm{I} .80(0.88)$ & $\mathrm{I} .2 \mathrm{I}(0.4 \mathrm{I})$ & $0.003^{c}$ \\
\hline \multicolumn{5}{|l|}{ Communication about CF in family ${ }^{b}$} \\
\hline We communicate openly about CF & 88 & $1.30(0.57)$ & I.I5 (0.36) & 0.205 \\
\hline We are good at supporting each other when CF takes up time & 88 & $1.65(0.85)$ & $1.29(0.52)$ & $0.044^{c}$ \\
\hline We can express our feelings towards each other regarding CF & 88 & $1.93(0.89)$ & $\mathrm{I} .53(0.7 \mathrm{I})$ & $0.034^{c}$ \\
\hline We can talk about everything concerning CF & 88 & $1.63(0.85)$ & $\mathrm{I} .35(0.54)$ & 0.188 \\
\hline We can talk about our anxiety concerning CF & 88 & $1.70(0.90)$ & $\mathrm{I} .47(0.56)$ & 0.421 \\
\hline We can communicate about CF even if we are depressed & 88 & $1.83(0.93)$ & I.4I (0.56) & $0.040^{c}$ \\
\hline
\end{tabular}

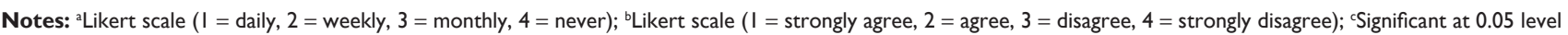
(two-tailed).

Abbreviations: CF, cystic fibrosis; SD, standard deviation.

lower the body mass index and the greater the digestive and respiratory symptoms. In reality, we are facing an association, but do not know what is cause and what is effect.

The significant associations between number of barriers and reactions from the mother, father, and adolescent and communication about cystic fibrosis in the family are consistent with findings at the single-item level (Table 6), showing that adolescents facing adherence barriers apparently had more quarrels with their parents and that these families were less likely to support one another. This correlates with other studies that found positive family factors to correlate with increased adherence. ${ }^{11}$ These findings are most interesting because they suggest that relationships and atmosphere within the family may partly shape the adolescent patient's perception of barriers to adherence and adherence itself.

A limitation of the present study is that the groups were not fully comparable. Participating adolescents had a statistically significantly higher $\mathrm{FEV}_{1} \%$ than the nonparticipating adolescents, and the participants included significantly more females than did the nonparticipants. Thus, bias may have arisen because patients with mild disease are more prone than patients with severe disease to participate in surveys, as are females compared with males. Use of web-based questionnaires may also be considered a limitation although, to our knowledge, no 
adolescents and only one parent did not have access to the Internet. Another limitation is the mean substitution of the answers "do not know", "does not get this treatment", and "not relevant", because several studies have shown that levels of adherence vary according to the type of treatment. ${ }^{23}$ Moreover, self-reporting involves a subjective element, and an objective electronic measure would have yielded more reliable data. ${ }^{23}$ It may also be argued that correction for Type I error should have been included because of the multiple correlations. However, we found correlations without correction for Type 1 errors to be appropriate because the comparisons were actually expected and not performed just to see what might appear. ${ }^{24}$ The present study reports patient-related and treatment-related barriers, and hence does not take patient-provider factors into account, even if they may play a role, as suggested in organ transplant research. ${ }^{25}$ Differences in the methods used to measure barriers to adherence hinder any comparison of outcomes. Another limitation is the lack of use of validated measures. Barrier scales have been developed and validated for adolescents with other diseases ${ }^{14,15}$ but, to our knowledge, not yet for adolescents with cystic fibrosis. This would be instrumental in furthering our understanding of adherence issues in this patient group.

\section{Conclusion}

Treatment adherence is crucial to patients with cystic fibrosis. This exploratory study showed that the majority of adolescents with cystic fibrosis and their parents experienced barriers to treatment adherence. The agreement between adolescents and their parents regarding the level and types of barriers that exist affords an opportunity for close cooperation between adolescents, their parents, and health care professionals in overcoming adherence problems. Further research is needed to unearth the etiology of poor adherence and to design effective intervention to improve adherence.

\section{Disclosure}

The authors report no conflicts of interest in this work.

\section{Acknowledgments}

This study was supported by three grants, one from the Danish Cystic Fibrosis Association, one from the Novo Nordisk Foundation, and one from the Danish Nurses Organization Foundation. We are grateful to the patients and families who participated in this research.

\section{References}

1. Eakin MN, Bilderback A, Boyle MP, Mogayzel PJ, Riekert KA. Longitudinal association between medication adherence and lung health in people with cystic fibrosis. J Cyst Fibros. 2011;10(4):158-164.

2. Patterson JM, Goetz D, Budd J, Warwick WJ. Family correlates of a 10-year pulmonary health trend in cystic fibrosis. Pediatrics. 1993;91(2):383-389.

3. Zindani GN, Streetman DD, Streetman DS, Nasr SZ. Adherence to treatment in children and adolescent patients with cystic fibrosis. J Adolesc Health. 2006;38(1):13-17.

4. Masterson TL, Wildman BG, Newberry BH, Omlor GJ. Impact of age and gender on adherence to infection control guidelines and medical regimens in cystic fibrosis. Pediatr Pulmonol. 2011;46(3):295-301.

5. White H. Dietary intakes in adult patients with cystic fibrosis - do they achieve guidelines? J Cyst Fibros. 2004;3(1):1-7.

6. Chappell F, Williams B. Rates and reasons for non-adherence to home physiotherapy in paediatrics: pilot study. Physiotherapy. 2002;88(3): $138-147$.

7. Patterson JM, Wall M, Berge J, Milla C. Gender differences in treatment adherence among youth with cystic fibrosis: Development of a new questionnaire. J Cyst Fibros. 2008;7(2):154-164.

8. Quittner AL, Modi AC, Lemanek KL, Ievers-Landis CE, Rapoff MA. Evidence-based assessment of adherence to medical treatments in pediatric psychology. J Pediatr Psychol. 2008;33(9):916-936.

9. Williams B, Mukhopadhyay S, Dowell J, Coyle J. Problems and solutions: accounts by parents and children of adhering to chest physiotherapy for cystic fibrosis. Disabil Rehabil. 2007;29(14):1097-1105.

10. Myers LB, Horn SA. Adherence to chest physiotherapy in adults with cystic fibrosis. J Health Psychol. 2006;11(6):915-926.

11. DeLambo KE, Ievers-Landis CE, Drotar D, Quittner AL. Association of observed family relationship quality and problem-solving skills with treatment adherence in older children and adolescents with cystic fibrosis. J Pediatr Psychol. 2004;29(5):343-353.

12. White T, Miller J, Smith GL, McMahon WM. Adherence and psychopathology in children and adolescents with cystic fibrosis. Eur Child Adolesc Psychiatr. 2008;18(2):96-104.

13. Modi AC, Quittner AL. Barriers to treatment adherence for children with cystic fibrosis and asthma: what gets in the way? J Pediatric Psychol. 2006;31(8):846-858.

14. Logan D. The illness management survey: identifying adolescents' perceptions of barriers to adherence. J Pediatr Psychol. 2003;28(6):383-392.

15. Simons LE, McCormick ML, Devine K, Blount RL. Medication barriers predict adolescent transplant recipients' adherence and clinical outcomes at 18-month follow-up. J Pediatr Psychol. 2010;35(9):1038-1048.

16. George M, Rand-Giovannetti D, Eakin MN, et al. Perceptions of barriers and facilitators: Self-management decisions by older adolescents and adults with CF. J Cyst Fibros. 2010;9(6):425-432.

17. Dziuban EJ, Saab-Abazeed L, Chaudhry SR, Streetman DS, Nasr SZ. Identifying barriers to treatment adherence and related attitudinal patterns in adolescents with cystic fibrosis. Pediatr Pulmonol. 2010;45(5): $450-458$.

18. Nunnally J. Psychometric Theory. New York, NY: McGraw-Hill; 1978.

19. Myers K, Winters NC. Ten-year review of rating scales. I Overview of scale functioning, psychometric properties, and selection. J Am Acad Child Adolesc Psychiatr. 2002;41(2):114-122.

20. Bregnballe V, Thastum M, Lund LD, et al. Validation of the Danish version of the revised cystic fibrosis quality of life questionnaire in adolescents and adults (CFQ-R14+). J Cyst Fibros. 2008;7(6):531-536.

21. Badlan K. Young people living with cystic fibrosis: an insight into their subjective experience. Health Soc Care Community. 2006;14(3): 264-270.

22. Fitzgerald D. Non-compliance in adolescents with chronic lung disease: causative factors and practical approach. Paediatr Respir Rev. 2001; 2(3):260-267. 
23. Modi A, Lim C, Yu N, et al. A multi-method assessment of treatment adherence for children with cystic fibrosis. J Cyst Fibros. 2006;5(3): 177-185.

24. Armitage P, Berry G, Matthews JNS. Statistical Methods in Medical Research. 3rd ed. Oxford, UK: Blackwell Scientific Publications; 1994.
25. O’Grady JGM, Asderakis A, Bradley R, et al. Multidisciplinary insights into optimizing adherence after solid organ transplantation. Transplantation. 2010;89(5):627-632.

Patient Preference and Adherence

\section{Publish your work in this journal}

Patient Preference and Adherence is an international, peer-reviewed, open access journal focusing on the growing importance of patient preference and adherence throughout the therapeutic continuum. Patien satisfaction, acceptability, quality of life, compliance, persistence and their role in developing new therapeutic modalities and compounds to optimize clinical outcomes for existing disease states are major areas of interest. This journal has been accepted for indexing on PubMed Central. The manuscript management system is completely online and includes a very quick and fair peer-review system. Visit http://www.dovepress.com/ testimonials.php to read real quotes from published authors.

Submit your manuscript here: http://www.dovepress.com/patient-preference-and-adherence-journal 